\title{
Longitudinal Change in Parent-Adolescent Communication About Sexuality
}

Laura M. Padilla-Walker

Brigham Young University, laura_walker@byu.edu

Follow this and additional works at: https://scholarsarchive.byu.edu/facpub

Part of the Social and Behavioral Sciences Commons

\section{Original Publication Citation}

Padilla-Walker, L. M. (2018). Longitudinal change in parent-child communication about sexuality. Journal of Adolescent Health, 63, 753-758.

\section{BYU ScholarsArchive Citation}

Padilla-Walker, Laura M., "Longitudinal Change in Parent-Adolescent Communication About Sexuality" (2018). Faculty Publications. 5507.

https://scholarsarchive.byu.edu/facpub/5507

This Peer-Reviewed Article is brought to you for free and open access by BYU ScholarsArchive. It has been accepted for inclusion in Faculty Publications by an authorized administrator of BYU ScholarsArchive. For more information, please contact ellen_amatangelo@byu.edu. 
Original article

\title{
Longitudinal Change in Parent-Adolescent Communication About Sexuality
}

\author{
Laura M. Padilla-Walker, Ph.D.* \\ School of Family Life, Brigham Young University, Provo, Utah
}

Article History: Received May 9, 2018; Accepted June 29, 2018

Keywords: Parent-child sex communication; Sex education; Parenting; Adolescents; Longitudinal

\section{A B S T R A C T}

Purpose: Research suggests that parents can be important sources of sex education for their children, but we know little about how this type of communication changes developmentally. Thus, the current study explored longitudinal change in child-, mother-, and father-reports of parent-child communication about sexuality, and how change might be associated with behaviors indicative of sexual risk.

Methods: The sample included 468 adolescents (52\% female, 67\% white) who participated every year from age 14 to 18 , and their mother and father.

Results: Growth-curve analyses revealed relatively low and stable levels of parent-child communication from all three reporters, with some differences as a function of reporter and child gender. Results also suggested that initial levels and change in parent-child communication over time were associated with child-reports of safer sex at the final time point (age 21).

Conclusions: The discussion focuses on developmental approaches to parent-child sex communication and the need for future research.

(C) 2018 Society for Adolescent Health and Medicine. All rights reserved.

\section{IMPLICATIONS AND CONTRIBUTION STATEMENT}

This study provides evidence of change over time in parent-child sex communication, with important implications for prevention research. Findings suggest low and stable levels of sex communication from early to late adolescence. Initial levels and increases in communication were associated with safer sex at age 21 .
The 2015 Youth Risk Behavior Report revealed some mixed and potentially troubling results. Namely, though teens reported having less sex overall (teens reporting being sexually active was $30 \%$, down from $34 \%$ in 2013), those who were having sex reported less condom use (57\% in 2015 compared to $63 \%$ in 2003). This suggests that the increase in condom use we saw through the early 2000s is on the decline, perhaps as a result of decreases in sex education in the past 10 years [1]. Whereas sex education has decreased over this time through formal avenues such as schools, sex education from parents has not declined over time. In a recent review of 21 st century parentchild sex communication in the United States, Flores and Barroso [2]

Conflict of interest: There are no conflicts of interest or financial relationships to disclose.

* Address correspondence to: Laura M. Padilla-Walker, School of Family Life, Brigham Young University, 2071 JFSB, Provo, UT 84602.

E-mail address: laura_walker@byu.edu (L.M. Padilla-Walker). identified parents as a prime source of sex education for children because they are able to provide information and answer questions early and over time according to the child's needs. Despite parents playing an important role, it is well established that parents report higher levels of sex communication than do children [3], and that communication is most frequent between mothers and daughters [4]. We also know little about how sex communication changes over time, and how this might differ as a function of reporter and child gender. Given that parents are lauded as sex educators because of their opportunity to teach children early and over time, and because most of these conversations take place during adolescence, the consideration of longitudinal change in sex communication from early to late adolescence is particularly relevant and may be important for prevention and intervention efforts targeting adolescent sexuality. Thus, the current study explored longitudinal change in sex communication as reported by children (and their mothers and fathers) every year from age 14 to 18 , as well as the links between longitudinal change in sex communication and children's sexual behavior at age 21 . 


\section{Parent-child sex communication}

Parent-child sex communication consists of reciprocal communication between children and their parents about sexuality. The majority of sex communication in the United States is characterized as a one-time "birds and the bees" conversation between parents and children [2] that is often uncomfortable for both parties. That being said, a recent meta-analysis concluded that when parents do communicate with their children about sex, parents play a protective role against risky sex [5], including increased condom use and protection from sexually transmitted diseases (STDs) and HIV [2]. Though few studies have assessed longitudinal protection, one study found that mother-daughter communication about sexual risk was associated with fewer incidences of unprotected sex three months later [6], suggesting that sex communication is effective in a short-term longitudinal framework, but telling us little about the potential long-term protective associations.

Research assessing change over time has found that trends in parent-child discussions with daughters about STDs and birth control declined from 1995 to 2002 [7], but sex communication with parents did not change from 2006 to 2013 [1]. However, for both of these studies retrospective reports were used and individual change over time was not assessed. The only other studies found that assessed sex communication over a significant period of time were with college students or used retrospective reports, suggesting that we know little about developmental change in sex communication across adolescence. One would certainly expect that because of emotional and cognitive gains during adolescence, and changes in the parent-adolescent relationship toward more autonomy granting [8], there would be significant growth in the amount of sex communication that occurs across adolescence. However, given the high reports of one-time conversations about sex and parents general lack of willingness to acknowledge their children as sexual beings [2], it is also possible that little change occurs in sex communication across adolescence. In the current study we sought to understand whether parent-child sex communication changed or stayed stable over time. Despite increases in autonomy and mutuality in the parent-child relationship over time [8], given the unique challenges parents have discussing sex with their children we did not expect dramatic change over time, though we had no specific hypotheses given the dearth of research in this area.

Theoretical models taking a life-span perspective on communication highlight that people of different ages (in this case children and parents) have had different life events and are coming from different developmental places, which may make intergenerational communication challenging and incongruent [9]. With that in mind, and given research suggesting differences in sex communication as a function of parent and child gender [2], we expected that children would report lower levels of sex communication than would parents, and that daughters would receive more sex communication than would sons. We also expected that initial levels and especially positive change in sex communication over time would be associated with lower levels of sexual risk behavior at age 21.

\section{Methods}

\section{Participants and procedures}

Participants were 468 adolescents (52\% female, $67 \%$ white, and $90 \%$ heterosexual) and their mothers, and 311 fathers who were taken from a longitudinal study of adolescent development within the family $(N=500)$. Sixty-seven percent of families were two-parent (90\% biological, $6 \%$ step-families, and $4 \%$ adoptive) and $33 \%$ were single mothers ( $85 \%$ biological, $15 \%$ adopted). Forty-one percent of the sample reported less than $\$ 40,000$ combined household income annually, with the average household income around $\$ 60,000$ annually. In terms of religious affiliation, $51 \%$ of the sample reported being protestant, $11 \%$ Catholic, $23 \%$ other, and $15 \%$ unaffiliated.

After being granted IRB approval by the sponsoring University, at Wave 1 of the larger project participants whose children were between the ages of 11 and 14 were identified using a national telephone directory and were randomly selected from a large northwestern city to reflect the demographics of local census (in regards to income and ethnicity). The overall response rate of eligible families that were contacted and invited to participate was $61 \%$, which resulted in a total of 500 families (468 of which were still in the study at age 14). Families were contacted every year in the summer for 10 years. Longitudinal retention was over $90 \%$, and there were no differences on study variables between those who participated and those who dropped out of the study. Because of a four-year age gap in data collected by wave, data in the current study were restructured by age to more accurately assess growth. Thus, participants' data were assessed when teens were $14,15,16$, 17 , and 18 regardless of what wave they were in at this age. This resulted in a larger proportion of missing data at ages 14 and 18 (because sexuality measures were not included at all waves), but this data is considered to be missing completely at random. Missing data were dealt with using Full Information Maximum Likelihood (FIML) in MPLUS, so the full sample of 468 adolescents was used in the growth curve analyses. Sexual behavior outcomes were only measured at the final wave of the study (when participants were an average age of 21). Families were administered questionnaires by research assistants in their homes for the first five years of the study and were given online questionnaires for subsequent years. To encourage anonymity when answering questions in the home, children filled out questionnaires in a room separate from parents.

\section{Measures}

Parent-child communication about sexuality. Children, mothers, and fathers responded to a four-item measure every year from ages 14 to 18 assessing parent-child communication about sexuality and avoiding sexual risk. Items were adapted for this study from a national survey on sexuality [10] (e.g., "In the last year, how often have you talked with your child/parents about preventing pregnancy?"). Additional items with the same stem included, "how to use condoms or other protection during sexual activity", "protecting against STDs", "protecting against AIDS". Items were on a scale ranging from 1 (never) to 4 (often), and higher scores indicated higher levels of parent-child communication ( $\alpha$ ranged from .91 to .95 ).

Risky sexual behavior. At age 14, adolescents were asked whether they had ever had sexual intercourse (yes or no), and this was used as a control in longitudinal analyses. Adolescents reported on their own sexual behaviors at the final time point (average age of 21) with items adapted from the Sexual Risk Survey [11]. Adolescents responded to a number of open-ended questions that are indicative of sexual risk, including "How old were you when you first had sexual intercourse?" (age of first intercourse). Five questions about casual sex were summed (e.g., "In the past six months, 
how many times have you had sex with someone you did not know well or just met?", "How many people have you had sex with that you know but are not involved with in any sort of relationship (e.g., "friends with benefits"), "How many times have you had sex with a partner before knowing sexual histories"), with higher scores indicative of higher levels of casual sex. Finally, four questions were asked about safer sex (e.g., "the last time you had sexual intercourse, did you or your partner use a condom", same stem was used for additional items "an intrauterine device (IUD)", "birth control pills", and "any other type of protection"). Affirmative responses were summed on these four items to create a safer sex score, with higher scores indicating use of multiple forms of protection when having sexual intercourse (ranging from 0 to 4 ).

\section{Results}

Descriptive statistics of all study variables are in Table 1. Correlations between the three reporters of parent-child communication at five ages ranged from .13 to $.58(p<.05)$. To address the first research question, MPLUS software was used to conduct growth curve analyses separately for child-, mother-, and fatherreports of communication about sexuality from ages 14 to 18 (see Figure 1). Intercepts and slopes were explored using the MODEL TEST command to determine if they differed as a function of reporter and child gender. The child-reported model had good model fit $\left(X^{2}(6)=11.97, p=.06\right.$, comparative fit index $(C F I)=.98$, root mean square error of approximation (RMSEA) $=.05$ ) and had a significant intercept $(M=1.75, p<.001)$, a non-significant slope $(\mathrm{S}=.02, p=.67)$, and a non-significant quadratic $(\mathrm{Q}=-.00, p=.77)$. The mother-reported model had good model fit $\left(X^{2}(9)=25.51\right.$, $p=.002, \mathrm{CFI}=.98, \mathrm{RMSEA}=.06)$ and had a significant intercept $(\mathrm{M}=2.16, p<.001)$ and a significant slope $(\mathrm{S}=.06, p<.001)$. The father-reported model had good model fit $\left(X^{2}(1)=1.21, p=.27\right.$, $\mathrm{CFI}=.99, \mathrm{RMSEA}=.03)$ and had a significant intercept $(\mathrm{M}=1.73$, $p<.001)$, a marginally significant slope $(S=.13, p=.07)$ and a nonsignificant quadratic $(\mathrm{Q}=-.03, p=.13)$.

Table 1

Descriptive statistics of all study variables

\begin{tabular}{lrrrr}
\hline Variable & N & M & SD & Range \\
\hline SexCom14_CR & 107 & 1.75 & .86 & $1-4$ \\
SexCom15_CR & 280 & 1.75 & .89 & $1-4$ \\
SexCom16_CR & 393 & 1.77 & .91 & $1-4$ \\
SexCom17_CR & 452 & 1.78 & .86 & $1-4$ \\
SexCom18_CR & 375 & 1.81 & .94 & $1-4$ \\
SexCom14_MR & 108 & 2.04 & .93 & $1-4$ \\
SexCom15_MR & 278 & 2.13 & .87 & $1-4$ \\
SexCom16_MR & 388 & 2.29 & .97 & $1-4$ \\
SexCom17_MR & 444 & 2.38 & .98 & $1-4$ \\
SexCom18_MR & 334 & 2.32 & .97 & $1-4$ \\
SexCom14_FR & 69 & 1.76 & .78 & $1-4$ \\
SexCom15_FR & 194 & 1.84 & .83 & $1-4$ \\
SexCom16_FR & 270 & 1.87 & .85 & $1-4$ \\
SexCom17_FR & 296 & 1.86 & .83 & $1-4$ \\
SexCom18_FR & 229 & 1.86 & .88 & $1-4$ \\
Age of first intercourse21 & 308 & 16.64 & 1.83 & $10-22$ \\
Casual sex21 & 308 & 1.94 & 3.60 & $0-35$ \\
Safer sex21 & 308 & 1.08 & .77 & $0-4$ \\
\hline
\end{tabular}

Note. $\mathrm{CR}=$ Child-report; FR = Father-report; MR = Mother-report; Numbers after variable = age of adolescent; SexCom = sexual communication. All SexCom variables were estimated in MPLUS using FIML for missing values so the full sample of 468 was used for growth curve analyses. $\mathrm{N}$ for sexual behavior variables only includes those who reported having had sex at the final time point $(\mathrm{N}=308$ of the 423 who had complete data at the final time point, or $73 \%$ of the sample).
The intercept and slope of all three growth curves were constrained to be equal to determine differences as a function of reporter. Model fit decreased when the intercept of child-and mother-reported models were constrained (Wald $=44.35, p<$ .001 ), and when the intercept of mother-and father-reported models were constrained (Wald $=17.14, p<.001$ ), but not when the intercept of child- and father-reported models were constrained (Wald $=3.03, n s$ ). In addition, model fit decreased when the slope of child-and mother-reported models were constrained (Wald $=8.39, p<.01$ ), but not when the slope of child- and fatherreported models were constrained (Wald $=.89$, ns.) or when the slope of mother- and father-reported models were constrained (Wald $=3.38$, ns.). Taken together this suggests that the intercept of mother-reported sexual communication was higher than both child- and father reports, and the slope of mother-reported communication was steeper than that of child-reports.

Intercept and slope of all three models were also constrained to determine if they varied as a function of child gender. The childand father-reported models did not differ as a function of gender of the child, but the mother-reported model did (Wald $=8.64$, $p=.01$ ). The unconstrained growth curve suggested that the intercept for boys was lower $(\mathrm{M}=1.99, p<.001)$ than for girls $(\mathrm{M}=2.29, p<.001)$ and the slope was positive for boys $(\mathrm{S}=.10$, $p<.001$ ) but non-significant for girls $(\mathrm{S}=.03, p=.19)$. As shown in Figure 2, mothers report talking with their sons less than their daughters in early adolescence, but by age 18 the levels of communication were equal.

Next a conditional model was conducted to explore how initial levels and change in parent-child communication about sexuality were associated with sexual risk behaviors at the final time point (average age of 21, controlling for whether or not teens had sexual intercourse at age 14). Behaviors included age of first intercourse, casual sex, and safer sex. The child-reported model suggested that the slope of communication was positively associated with safer sex at the final time point $(\beta=.31, p=.03)$. The father-reported model also suggested that the intercept of communication was marginally positively associated with safer sex at the final time point $(\beta=.13, p=.05)$. The mother-reported model suggested that the intercept $(\beta=.17, p<.01)$ and slope $(\beta=.31, p=.001)$ of communication were positively associated with safer sex at the final time point. Parent-child sex communication was not associated with age of first intercourse or casual sex for any reporter.

\section{Discussion}

Research has established that parent-child sex communication is associated with safer sex for teens [5], but few studies have explored longitudinal change in sex communication across adolescence. Thus, the current study examined change in sex communication from ages 14 to 18 , and how initial levels and longitudinal change were associated with risky sexual behaviors at age 21 . Current findings suggested that both child- and father-reports of sex communication were low and stable from early to late adolescence, while mother-reports were significantly higher (though still relatively low) than both child- and father-reports. Multiple group analyses with mother-reports suggested lower initial levels of sex communication with sons compared to daughters, but also significant positive increases over time in sex communication for boys, but not girls. These findings build meaningfully on existing research that suggests disparities in child and parent reports of sex communication [2,3], and highlight that mothers in particular might overestimate how much their children perceive 


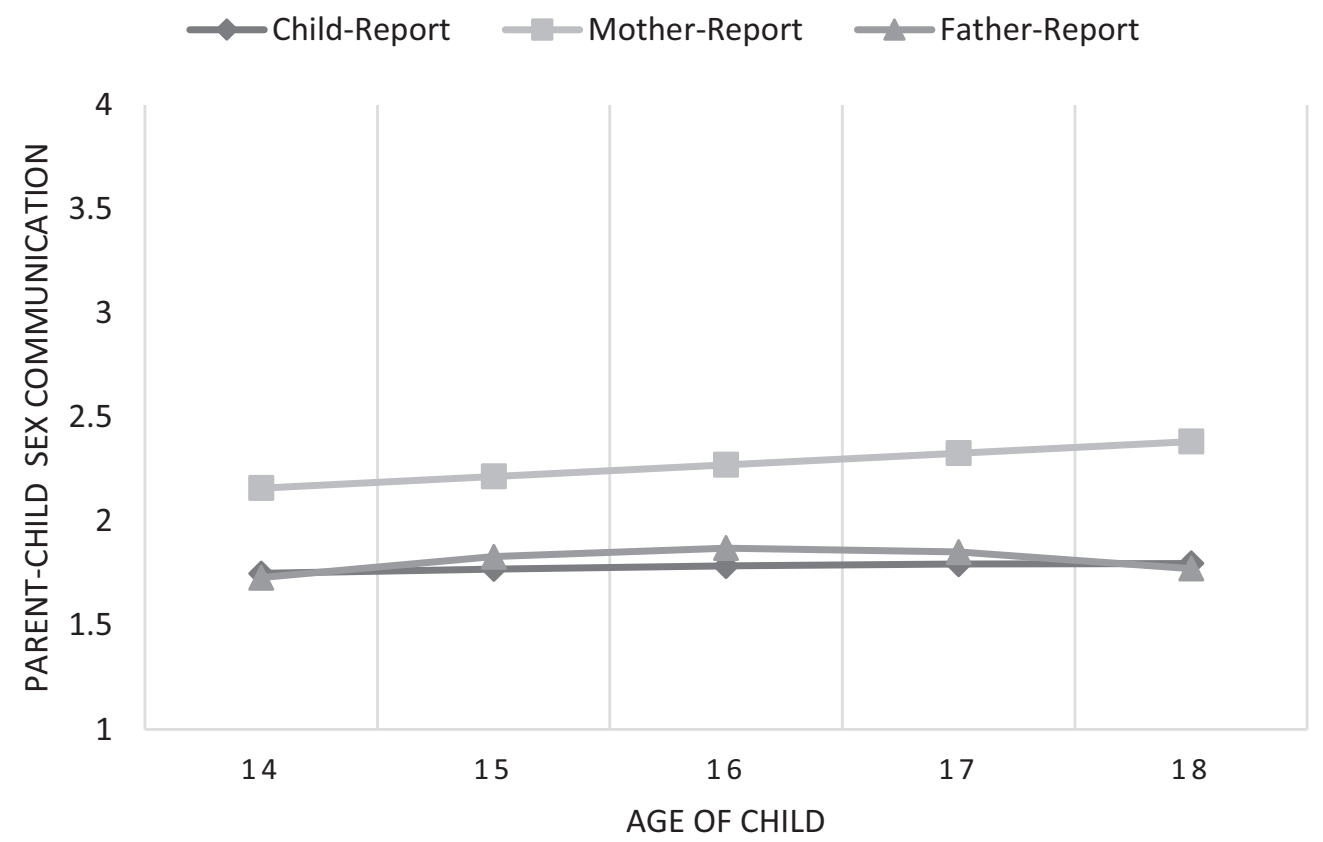

Figure 1. Child-, mother- and father-reports of parent-child sex communication.

conversations about sex are occurring. Unfortunately, because teens did not report on parents separately, it is difficult to determine if child- and father-reports were similar because fathers are more realistic than mothers, or because teens are not considering parents separately (and thus, lower father-child communication may be pulling the child-reported levels down). Future research should consider child-reports of both mothers and fathers separately so that the role of the father-child relationship in the socialization of sexuality can be more fully understood.
These findings are also consistent with research on trends in sex communication that suggest little change over time [1], but extend this research by addressing longitudinal change over time. These findings are somewhat disquieting, suggesting low and stable levels of sex communication across adolescence (for most reporters), despite developmental changes that should encourage increases in such conversations. An optimistic perspective would highlight that at least there was not a decline in frequency over time, but parents and prevention
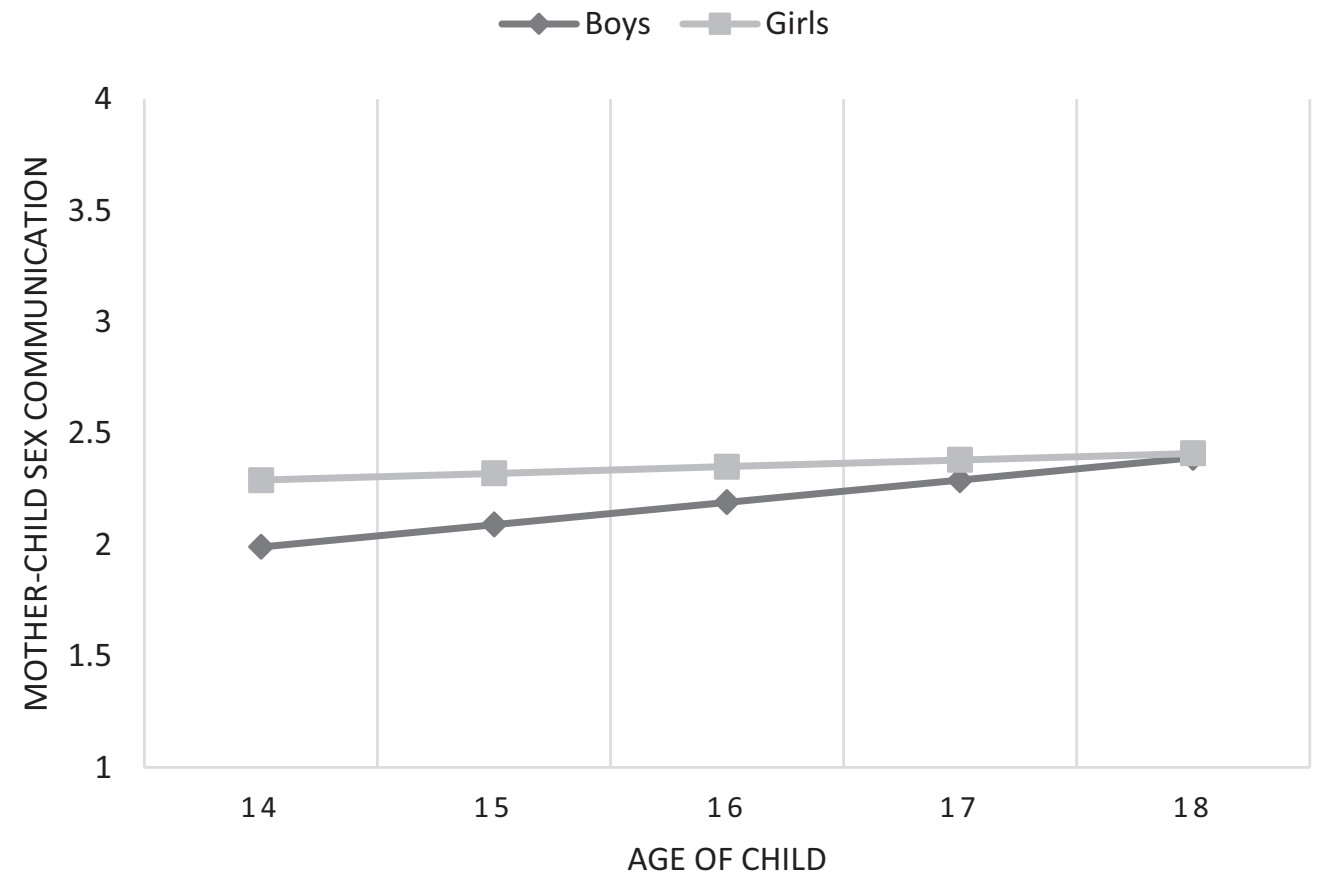

Figure 2. Mother-reports of parent-child communication about sexuality by child gender. 
efforts should continue to encourage proactive conversations that take place at higher frequency and that are of high quality [12], especially as children get older and are more likely to be sexually active [13].

Theoretical models of parent-child communication in general (without specific focus on sex-communication) suggest that parent-child communication continues to be important across childhood and adolescence, and that warmth messages (messages that allow children to feel cared for and supported) should increase or stay steady across adolescence, while control messages (or directives, declaratives) should decrease over time [14]. Though both family communication [14] and intergenerational communication [9] theories suggest that communication should certainly change in quality if not quantity across adolescence, the current measure of parent-child sex communication was not able to assess the nuances of quality of communication. Indeed, it is possible that while overall frequency of parent-child sex communication does not vary much across adolescence, the quality, depth, and breath of conversations parents are having may change significantly, especially as children transition to adulthood. Indeed, one study found that parent-child conversations about sex became more mutual and disclosing across four years in a sample of college students [15], suggesting that the change in not only frequency but quality of parent-child communication about sexuality is an important avenue to explore developmentally in future research.

Despite low overall levels of sex communication, current findings suggested that initial levels (father- and mother-reported models) and increases (child- and mother-reported models) in sex communication over time were associated with safer sex at age 21 for both boys and girls. These findings are consistent with crosssectional research [5], but extend this research by suggesting that not only are early conversations (at age 14) protective over time, but appropriate developmental increases in communication are also linked to safer sex during the transition to adulthood. This should increase the urgency that parents feel to have conversations with their children about sex, and educators and pediatricians should encourage parents to initiate conversations at least as soon as early adolescence, and with increasing frequency over time.

\section{Limitations and future directions}

Despite coming from the strength of a longitudinal design and multiple reporters, there are limitations to the current study. First, though the sample was representative of the area of the United States from which it was drawn in terms of income and ethnicity, it was not nationally representative and therefore may not be generalizable. Given research suggesting that sex communication varies as a function of variables such as ethnicity and income [5], a more diverse sample is desirable. The measure used in the current study of parentchild sex communication also had limitations, as it has not been rigorously validated in past research. Though the quality and nuances of measures of parent-child sex communication have improved over time, lack of high quality measurement is still a key limitation in the field as it stands [16], and future research should continue to develop more rigorously validated measures of this important aspect of parenting. Indeed, the current study focused only on parent-child conversations about sexual risk and protection as it related to sexual risk behaviors. Whereas this narrow focus is common, future research should cast a wider net to include broad indices of healthy sexuality (i.e., physical, emotional, and relational indicators of both sexual risk and sexual health) as well as more nuanced aspects of sex communication, such as quality [12]. For instance, frequency of sex communication may be less important than aspects of quality such as open, comfortable, and mutual conversation. Finally, future research should consider person-centered approaches to parent-child sex communication that assume heterogeneity in parent-child relationships. Indeed, whereas some parents may display consistently low levels of sex communication, others may have moderate or high levels that change over time. Differing developmental patterns or trajectories over time are not assessed in variable-centered approaches like those used in the current study, and should be the focus of future research to identify subgroups who may be at particular risk or who may be providing model examples of socialization.

Despite these limitations and the need for future research, the current study provides some of the first evidence of developmental change over time in parent-child sex communication. Overall findings suggest low and stable levels of sex communication from early to late adolescence, though mother-reports are higher and increase over time (especially for boys). Initial levels and increases in sex communication are associated with safer sex at age 21 . Taken together, findings encourage a developmental approach to parent-child sex communication and suggest that parents should talk with their children about sexuality earlier, more often, and at increasing levels as children get older. This may be especially important considering that formal sex education is decreasing for teens [1] and is not consistently effective [17].

\section{Acknowledgments}

We thank the Family Studies Center at BYU, the School of Family Life, and the College of Family Home and Social Science at BYU, and we recognize the generous support of the many private donors who provided support for this project. We also thank those families who were willing to spend valuable hours with our team in interviews, and the many students who assisted in conducting the interviews.

\section{References}

[1] Lindberg L, Maddow-Zimet I, Boonstra H. Changes in adolescents' receipt of sex education, 2006-2013. J Adolesc Health 2016;58:621-7.

[2] Flores D, Barroso J. 21st century parent-child sex communication in the United States: A process review. J Sex Res 2017;54:532-48.

[3] LaSala M. Condoms and connection: Parents, gay and bisexual youth, and HIV risk. J Marital Family Therapy 2015;41:451-64.

[4] Wisnieski D, Sieving R, Garwick A. Parent and family influences on young women's romantic and sexual decisions. Sex Educ 2015;15:144-57.

[5] Widman L, Noar S, Choukas-Bradley S, Francis D. Adolescent sexual health communication and condom use: A meta-analysis. Health Psychol 2014;33: $1113-24$.

[6] Hutchinson M, Jemmott J, Jemmott L, Braverman P, Fong G. The role of mother-daughter sexual risk communication in reducing sexual risk behaviors among urban adolescent females: A prospective study. J Adolesc Health 2003;33:98-107.

[7] Robert A, Sonenstein F. Adolescents' reports of communication with their parents about sexually transmitted diseases and birth control: 1988, 1995, and 2002. J Adolesc Health 2010;46:532-7.

[8] Soenens B, Vansteenkiste M, Beyers W. Parenting adolescents. In M. Bornstein (Ed.), Handbook of parenting 3e, Volume 1: Parenting across the lifespan. Abingdon, United Kingdom: Routledge; 2008.

[9] Williams A, Nussbaum J. Intergenerational communication across the life span [e-book]. Mahwah, NJ, US: Lawrence Erlbaum Associates Publishers; 2001. 
[10] Albert B. With one voice 2010: America's adults and teens sound off about teen pregnancy. Washington, DC: The National Campaign to Prevent Teen and Unplanned Pregnancy; 2010.

[11] Turchik J, Garske J. Measurement of sexual risk taking among college students. Arch Sex Behav 2009;38:936-48.

[12] Rogers A, Ha T, Stormshak E, Dishion T. Quality of parent-adolescent conversations about sex and adolescent sexual behavior: An observational study. J Adolesc Health 2015;57(2):174-8.

[13] Beckett M, Elliott M, Schuster M, et al. Timing of parent and child communication about sexuality relative to children's sexual behaviors. Pediatrics 2010;125:34-42.
[14] Segrin C, Flora J. Family communication. 2nd Ed e-book New York, NY, US: Routledge/Taylor \& Francis Group; 2011.

[15] Morgan E, Thorne A, Zurbriggen E. A longitudinal study of conversations with parents about sex and dating during college. Dev Psychol 2010;46:139-50

[16] Lefkowitz E. Beyond the yes-no question: Measuring parent-adolescent communication about sex. Talking sexuality: Parent-adolescent communication [e-book]. San Francisco, CA, US: Jossey-Bass. p. 43-56.

[17] Denford S, Abraham C, Campbell R, Busse H. A comprehensive review of reviews of school-based interventions to improve sexual-health. Health Psychol Rev 2017;11:33-52. 